\title{
To be screened or not to be screened? Modeling the consequences of PSA screening for the individual
}

\author{
EM Wever,', J Hugosson ${ }^{2}$, EAM Heijnsdijk', CH Bangma ${ }^{3}, \mathrm{G}$ Draisma' and HJ de Koning' \\ 'Department of Public Health, Erasmus Medical Center, PO Box 2040, Rotterdam 3000 CA, The Netherlands; '² Department of Urology, Sahlgrenska \\ University Hospital, Bruna stråket I I B, 4 I 345, Göteborg, Sweden; ${ }^{3}$ Department of Urology, Erasmus Medical Center, PO Box 2040, Rotterdam 3000 \\ $C A$, The Netherlands
}

\begin{abstract}
BACKGROUND: Screening with prostate-specific antigen (PSA) can reduce prostate cancer mortality, but may advance diagnosis and treatment in time and lead to overdetection and overtreatment. We estimated benefits and adverse effects of PSA screening for individuals who are deciding whether or not to be screened.

METHODS: Using a microsimulation model, we estimated lifetime probabilities of prostate cancer diagnosis and death, overall life expectancy and expected time to diagnosis, both with and without screening. We calculated anticipated loss in quality of life due to prostate cancer diagnosis and treatment that would be acceptable to decide in favour of screening.

RESULTS: Men who were screened had a gain in life expectancy of 0.08 years but their expected time to diagnosis decreased by 1.53 life-years. Of the screened men, $0.99 \%$ gained on average 8.08 life-years and for $17.43 \%$ expected time to diagnosis decreased by 8.78 life-years. These figures imply that the anticipated loss in quality of life owing to diagnosis and treatment should not exceed $4.8 \%$, for screening to have a positive effect on quality-adjusted life expectancy.

CONCLUSION: The decision to be screened should depend on personal preferences. The negative impact of screening might be reduced by screening men who are more willing to accept the side effects from treatment.

British Journal of Cancer (2012) I 07, 778-784. doi:I0.1038/bjc.2012.317 www.bjcancer.com
\end{abstract}

Published online 17 July 2012

(c) 2012 Cancer Research UK

Keywords: life expectancy; prostate cancer; screening; utility

The purpose of screening with prostate-specific antigen (PSA) is to reduce the risk of dying from prostate cancer by finding and treating prostate cancers at an early stage. The European Randomized study of Screening for Prostate Cancer (ERSPC) and the Göteborg trial (part of the ERSPC) showed that a reduction in prostate mortality can be obtained by screening with PSA (Schroder et al, 2009; Hugosson et al, 2010). However, an adverse effect of screening is overdiagnosis, i.e., the detection of cancers that would not have been diagnosed during the patients' lifetime if they had not been screened (Welch and Albertsen, 2009). Also, all men with screen-detected prostate cancer have to live more years with the knowledge that they have prostate cancer (lead-time). Men with screen-detected prostate cancer who opt for curative treatment risk living many years with the side effects of treatment, which would otherwise be symptom-free years (Korfage et al, 2005; Heijnsdijk et al, 2009).

Most major US medical organisations (Lim and Sherin, 2008; Smith et al, 2010; Wolf et al, 2010) and the European Association of Urology (Heidenreich et al, 2011) recommend that clinicians discuss the potential benefits and adverse effects of PSA screening with their clients, consider their clients' preferences, and individualise screening decisions. Information on the consequences of PSA screening on a persons' life can help in making an informed decision.

*Correspondence: EM Wever; E-mail: e.m.wever@erasmusmc.n Received 20 March 2012; revised 20 June 2012; accepted 26 June 20I2; published online 17 July 2012
This paper presents results of a simulation model showing the major differences between the potential course of lives of men who decide to be screened and those of men who decide not to be screened. We present the lifetime probability of prostate cancer diagnosis and death, overall life expectancy and expected prediagnosis life-years (the average life-years till the time of prostate cancer diagnosis) for the two groups. Though several studies have presented benefits and adverse effects of PSA screening for a population (Schroder et al, 2009; Welch and Albertsen, 2009; Hugosson et al, 2010), we present the consequences of screening from the time of the decision to be screened or not. Also, while in empirical studies harms and benefits are calculated after a followup time of some years, this study presents results for the whole lifetime.

Health economists use the concept of utility to express quantitatively adverse effects of diagnosis and treatment on quality of life. In this view, life without prostate cancer has utility 1; after diagnosis and treatment utility decreases to a lower level, depending on individual preferences and the specific consequences of diagnosis and treatment. Several authors have obtained estimates of utility or quality of life of living with these consequences (Steineck et al, 2002; Stewart et al, 2005; Dale et al, 2008; Carlsson et al, 2011). Although we do not estimate the utility and quality of life of living with prostate cancer, our results do allow calculation of the utility level below which the expected harms of early diagnosis exceed the expected gains from prevented prostate cancer mortality (the break-even point), which can be compared with individual expectations. 


\section{METHODS}

We used the MISCAN (MIcrosimulation SCreening ANalysis) prostate cancer model. MIcrosimulation SCreening ANalysis is a microsimulation programme that simulates the progression and screening of prostate cancer. The model was validated on prostate cancer detection data from the ERSPC Rotterdam (Draisma et al, 2003, 2006; Wever et al, 2010) and the ERSPC Göteborg (Hugosson et al, 2004), and on the mortality reduction data from the overall ERSPC trial (Schroder et al, 2009; Wever et al, 2011). The assumptions of the model and the estimation of the parameters are explained next in this section. For this analysis a cohort model was used, with the age of first screening distributed uniformly from age 50 to 70 and with subsequent screening until age 75 . The lifetime risks of prostate cancer diagnosis and death were calculated for the situation in which there was no screening and that with annual screening.

\section{MISCAN model}

A detailed description of the model and the data sources that informed the quantification of the model can be found in previous studies (Draisma et al, 2003, 2006; Wever et al, 2010, 2011) and also in a standardised model profile: http://cisnet.cancer.gov/ prostate/profiles.html. MIcrosimulation SCreening ANalysis is a microsimulation programme that simulates the progression of prostate cancer in individuals as a sequence of preclinical, clinical and screen-detected tumour states. First, the age at death from other causes is simulated per individual using Dutch life tables (Statistics Netherlands, 2000-2007). Next, the progression of prostate cancer in the absence of screening is simulated. Prostate cancer may develop from no prostate cancer to a clinically diagnosed cancer through one or more screen-detectable preclinical stages. From each preclinical stage, a tumour may grow to the next clinical T-stage (T1, impalpable; T2, palpable, confined to the prostate; $\mathrm{T} 3+$, palpable, with extensions beyond the prostatic capsule); it may dedifferentiate to a higher Gleason score (well differentiated, Gleason score 2-6; moderately differentiated, Gleason score 7; poorly differentiated and Gleason score 8-10); or it may be clinically diagnosed. For these transitions, the time spent in the current stage is generated from a Weibull distribution, where the parameters depend on the current stage and the choice of next stage is determined by transition probabilities. In addition, there is a risk that a tumour in the local regional stage (M0) will develop into disseminated disease (M1), which is modelled by using a stage and Gleason score-specific hazard function. Depending on the frequency and sensitivity of the screening test, preclinical cancers may be detected by screening. Prostate-specific antigen test and subsequent biopsy were modelled as a single test, where the sensitivity parameter was assumed to be clinical T-stage dependent. In the model, sensitivity is defined as the probability that a preclinical tumour is detected by a screening test at the time the test is taken.

Model parameters, including transition probabilities, mean dwelling times (the time from one preclinical state to another preclinical or clinical state) and stage-specific test sensitivities were estimated by constructing models for the ERSPC-Rotterdam and Göteborg, and by calibrating the model to the following data observed at these centres: baseline incidence (National Cancer Registry data for 1991 (Visser et al, 1994)) and stage distribution in the Netherlands (Rotterdam cancer registry data 1992-1993 (Spapen et al, 2000)); baseline incidence in Sweden (1988-1992 (Parkin et al, 1997)); incidence, Gleason and stage distributions in the control arms of ERSPC-Rotterdam and Göteborg; and detection rates, interval cancer rates, Gleason and stage distributions in the screen arms of ERSPC-Rotterdam (Draisma et al, 2003, 2006; Wever et al, 2010) and Göteborg (Hugosson et al, 2004). Number of cases diagnosed, and Gleason and stage distributions in the control arms $v s$ those in the screen arms provide insight into disease progression through the various preclinical phases. Parameters were estimated by numerically minimising the deviance between the number of cases observed and the number of cases predicted by the models. Deviances were calculated by assuming the Poisson likelihood for incidence data and by assuming multinomial likelihood for stage distribution data. The parameters for incidence, clinical diagnosis and sensitivity were assumed to be country-specific. For the main results in this analysis we used the country-specific parameters corresponding to the Netherlands. The cohort models used for the analysis were constructed by changing the screening protocol of the ERSPCRotterdam model to the screening protocols considered in this study.

We assumed that if men are clinically diagnosed with prostate cancer, the time to death from prostate cancer is determined by prostate cancer-specific survival curves. Survival curves for men with no initial treatment were estimated on the basis of SEER (Surveillance, Epidemiology and End Results) data, specifically on cases diagnosed in the pre-PSA era (1983-1986). We assumed that all men diagnosed with prostate cancer receive radical prostatectomy. According to the results of (Bill-Axelson et al, 2011), we assumed that men receiving radical prostatectomy have a relative risk of 0.62 of dying from prostate cancer compared with men receiving no initial treatment. This analysis did not consider other treatments, such as radiation therapy and active surveillance, because of the limited published results about the effectiveness of these treatments. If the effectiveness of radiation therapy and active surveillance are different than that of radical prostatectomy, the results for these treatments will be different than those presented. For distant prostate cancer, we assumed that treatment has no effect. Some treatments might increase survival of distant disease slightly. However, in our view this is a minor limitation of the model.

The effect of early detection through screening on survival was included by assuming that a fraction of local-regional tumours detected by screening are cured because the tumours are treated earlier. The Gleason score-dependent cure rates were estimated by calibrating the ERSPC-Rotterdam model to the observed $27 \%$ prostate cancer mortality reduction in the overall ERSPC at followup after 9 years (Wever et al, 2011).

\section{Calculating utility break-even point}

We assigned being alive without diagnosed prostate cancer a utility of one, being dead a utility of zero, and being alive with diagnosed and treated prostate cancer a utility of $u$. The utility break-even point is the value of the utility of living with diagnosed and treated prostate cancer, $u$, for which the expected quality of life lost due to earlier detection and treatment of cancer is equal to the expected quality-adjusted life expectancy gained (Figure 1). Therefore, men who can judge that their reduction in quality of life in the event that they are diagnosed and treated for prostate cancer exceeds the reduction that is represented by this threshold utility should possibly refrain from screening participation.

\section{Sensitivity analyses}

To evaluate the statistical variation and uncertainty of the observed data, we conducted a number of sensitivity analyses. The sensitivity analyses compared models with various lead-times, incidence, survival curves and cure rates. Penalised optimisation was used to obtain a range of models with various lead-times. Parameters for these models were estimated by minimising the sum of total deviance and lead-time penalty (mean lead-time $\times$ penalty). The penalties used were -100 (favoring long leadtimes), 0 and 100 (favoring short lead-times). We varied incidence 
in the models by using estimated incidence parameters that reproduced incidence in the Netherlands or Sweden. Different survivals were considered by assuming a relative risk of $0.5,1$ or 2 on the hazard of prostate cancer death. The various cure rates were obtained by calibrating the ERSPC-Rotterdam model to a mortality reduction of $27 \%$ (observed for attendees in ERSPC), $44 \%$ (observed for the screen group in ERSPC-Göteborg) or $56 \%$ (observed for attendees in ERSPC-Göteborg).

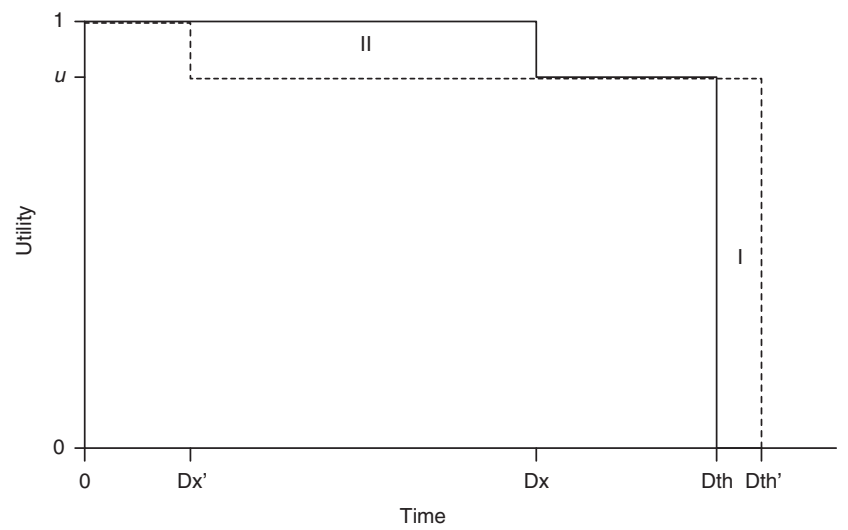

Figure I Harms and benefits in prostate cancer screening. Time 0 is the time of deciding to participate or not in screening. Utility or quality of life has value I until the moment of a prostate cancer diagnosis (Dx); the remaining lifetime until death (Dth) has utility $u<1$. The figure shows hypothetical utility curves for a person without (solid) and with screening (dashes). Screening may detect prostate cancer earlier (at time (Dx') and possibly postpone the moment of death (to time Dth'). Area I represents the gain in quality-adjusted life-years and area II the loss in quality of life due to earlier detection. The level $\mathrm{u}$ depends on the consequences of diagnosis and treatment. If the expected gain in quality-adjusted life-years (area I) equals the expected loss of quality of life due to earlier diagnosis (area II) the decision to participate in screening or not does not affect expected quality-adjusted life-years. The utility break-even point is the utility level corresponding to that situation.

\section{RESULTS}

Table 1 shows predicted risks of prostate cancer diagnosis and death and life expectancies for men aged 50-54, 55-59, 60-64 and $65-69$, both when deciding to participate in screening or not. As an illustration, consider men in the 55-59 age group. Men who had not been screened had a $14.44 \%$ lifetime risk of being diagnosed with prostate cancer and a $2.94 \%$ lifetime risk of dying from it. Life expectancy was 22.31 years, 21.08 of which pre-diagnosis. By comparison, those who participated in a yearly screening programme had a $21.54 \%$ lifetime risk of being diagnosed with prostate cancer, a $1.89 \%$ risk of dying from prostate cancer and a life expectancy of 22.40 years, 19.47 of which pre-diagnosis. Therefore, men screened annually increased their life expectancy by 0.09 years, i.e., 33 days. However, because of the lead-time inherent in screen detection their expected pre-diagnosis life-years decreased by 1.61 years, i.e., 588 days.

Though the 0.09 expected gain in life-years appears small, this is a weighted average of all men who were screened. Among men who were screened, a fraction of $1.05 \%(=2.94-1.89 \%)$ did not die of prostate cancer because the cancer was detected and treated earlier (Table 2). Life expectancy among these men increased by 8.57 years $(=0.09 \times 100 / 1.05)$. The expected loss of 1.61 pre-diagnosis life-years is also a weighted average. Among men who were screened, $17.73 \%$ were screen-detected with prostate cancer. Their expected pre-diagnosis life-years decreased by 9.08 years $(=1.61 \times 100 / 17.73)$.

Figure 2 presents the probability of being alive without diagnosed prostate cancer, alive with diagnosed prostate cancer, dead from prostate cancer, and dead from other causes at various points in time, from the time of the decision to be screened or not, and how these probabilities were affected by the decision. Patients in the health state alive with diagnosed prostate could be cured of their disease or not. This health state is a transient state that eventually will be absorbed by the state dead from prostate cancer or dead from other causes. The figures show that although screening reduced the probability of dying from prostate cancer in the long term, it substantially increased the probability of being alive with diagnosed prostate cancer in the short term. This pattern

Table I Predicted results of prostate cancer ( $P c)$ diagnosis and death

\begin{tabular}{|c|c|c|c|c|c|c|c|}
\hline Scenario & $\begin{array}{c}\text { Lifetime } \\
\text { probability of } \\
\text { pc diagnosis (\%) }\end{array}$ & $\begin{array}{c}\text { Lifetime } \\
\text { probability of pc } \\
\text { screen-detection (\%) }\end{array}$ & $\begin{array}{l}\text { Lifetime } \\
\text { probability of } \\
\text { pc death (\%) }\end{array}$ & $\begin{array}{l}\text { Pre-diagnosis } \\
\text { life-years }^{a}\end{array}$ & $\begin{array}{l}\text { Post-diagnosis } \\
\text { life-years }\end{array}$ & $\begin{array}{l}\text { Life } \\
\text { expectancy } \\
\text { (years) }\end{array}$ & $\begin{array}{l}\text { Utility } \\
\text { break-even } \\
\text { point }^{\text {b }}\end{array}$ \\
\hline \multicolumn{8}{|c|}{ Age at first screen 50-54 } \\
\hline No screening & 14.44 & 0.00 & 2.98 & 25.44 & 1.28 & 26.72 & - \\
\hline Annual screening & 21.38 & 17.62 & 1.91 & 23.81 & 2.99 & 26.81 & 0.947 \\
\hline \multicolumn{8}{|c|}{ Age at first screen 55-59 } \\
\hline No screening & 14.44 & 0.00 & 2.94 & 21.08 & 1.24 & 22.31 & - \\
\hline Annual screening & 21.54 & 17.73 & 1.89 & 19.47 & 2.93 & 22.40 & 0.949 \\
\hline \multicolumn{8}{|c|}{ Age at first screen 60-64 } \\
\hline No screening & 14.07 & 0.00 & 2.86 & 17.07 & 1.11 & 18.18 & - \\
\hline Annual screening & 21.38 & $|7.5|$ & 1.88 & 15.55 & 2.71 & 18.26 & 0.954 \\
\hline \multicolumn{8}{|c|}{ Age at first screen 65-69 } \\
\hline No screening & 13.35 & 0.00 & 2.64 & 13.50 & 0.93 & 14.43 & - \\
\hline Annual screening & 20.90 & 16.79 & 1.81 & 12.15 & 2.34 & 14.49 & 0.960 \\
\hline \multicolumn{8}{|c|}{ Age at first screen 50-69 (All) } \\
\hline No screening & 14.10 & 0.00 & 2.86 & 19.55 & 1.15 & 20.70 & \\
\hline Annual screening & 21.31 & 17.43 & 1.87 & 18.02 & 2.76 & 20.78 & 0.952 \\
\hline
\end{tabular}

${ }^{a}$ Expected life-years till the time of prostate cancer diagnosis. ${ }^{b}$ The utility break-even point is the value of the utility of living with diagnosed prostate cancer for which the utilityadjusted life expectancy does not change upon deciding to participate in screening or not. Its value decreases with larger gains in overall life expectancy relative to the expected loss in pre-diagnosis life-years. A high value of the utility break-even point means that men should only decide in favour of screening when they anticipate a small loss in quality of life owing to detection and possibly treatment of prostate cancer. 
is especially clear in older ages, who have a higher probability of having a preclinical prostate cancer, which is screen-detectable. For younger ages, too, screening substantially increased the probability of being alive with diagnosed prostate cancer, though in their case this increase was more widely distributed over the follow-up years.

Table 1 and Figure 2 can be used by clinicians and individuals to discuss the short- and long-term benefits and harms that apply to the average individual. To summarise the harms and benefits in one measure we calculated the utility break-even point. The utility break-even points were high $(0.947-0.960)$ for all ages. These utility break-even points imply that men who might judge, based on information given, that their quality of life will decrease by

Table 2 Percentage of population experiencing benefits and harms of prostate cancer $(p c)$ screening

\begin{tabular}{|c|c|c|c|}
\hline & $\begin{array}{c}\% \text { Of } \\
\text { population }\end{array}$ & $\begin{array}{l}\text { Decrease in } \\
\text { pre-diagnosis } \\
\text { life-years }\end{array}$ & $\begin{array}{c}\text { Increase in } \\
\text { life expectancy } \\
\text { (years) }\end{array}$ \\
\hline \multicolumn{4}{|l|}{ Age at first screen 55-59 } \\
\hline $\begin{array}{l}\text { Never diagnosed with pc } \\
\text { whether being screened } \\
\text { or not }\end{array}$ & 78.46 & 0.00 & 0.00 \\
\hline $\begin{array}{l}\text { Diagnosed with } p c \text { if being } \\
\text { screened, but never } \\
\text { diagnosed with } p c \text { if not } \\
\text { being screened }\end{array}$ & 7.10 & 10.69 & 0.00 \\
\hline $\begin{array}{l}\text { Diagnosed with } p c \text { and } \\
\text { dead from other causes } \\
\text { whether being screened } \\
\text { or not }\end{array}$ & 11.50 & 5.43 & 0.00 \\
\hline $\begin{array}{l}\text { Diagnosed with } p c \text { and } \\
\text { dead from } p c \text { whether } \\
\text { being screened or not }\end{array}$ & 1.89 & 6.97 & 0.00 \\
\hline $\begin{array}{l}\text { Diagnosed with pc whether } \\
\text { being screened or not, but } \\
\text { not dead from pc because } \\
\text { of early detection by } \\
\text { screening }\end{array}$ & 1.05 & 9.15 & 8.57 \\
\hline Weighted total & 100.00 & 1.61 & 0.09 \\
\hline
\end{tabular}

$>4.0-5.3 \%$ in the event that they are diagnosed and treated for prostate cancer should probably avoid being screened. It is important to note that the utility break-even points are estimated clinical outcomes from a population that applies to average individuals.

Varying lead-time, incidence, survival and cure rates caused the decrease in expected pre-diagnosis life-years to vary from 1.40 to 2.31 years, the increase in life expectancy to vary from 0.02 to 0.40 years and the utility break-even point to vary from 0.833 to 0.991 (Table 3). Shorter lead-times, more negative survival and higher cure rates yielded results more in favour of screening. Although the loss in quality of life acceptable for a man to consider screening was only $0.9 \%$ in the most unfavourable model for screening, the most favourable model showed a $16.7 \%$ loss as still being acceptable.

\section{DISCUSSION}

The analysis showed that if an individual decides to be screened, his lifetime risk of prostate cancer death decreased from 2.86 to $1.87 \%$, while his overall life expectancy increased by 0.08 years. At the same time, his lifetime risk of being diagnosed with prostate cancer increased from 14.10 to $21.31 \%$ and his expected prediagnosis life-years decreased by 1.53 years. A fractional percentage of $0.99 \%$ of screened men enjoyed a benefit of living an average of 8.08 years longer, whereas $17.43 \%$ of the screened men were screen-detected and lived an average of 8.78 pre-diagnosis life-years less. In many cases this means an increase in life-years suffering from morbidity associated with treatment (Potosky et al, 2000; Korfage et al, 2005).

Albertsen et al $(2005,2011)$ estimated risks of death from prostate cancer as a function of grade and age for prostate cancer left untreated (not treated curatively). His curves show that the risk of dying from prostate cancer is high for high-grade cancer only. His estimates are relevant for men diagnosed with prostate cancer who have to decide on treatment. Similarly, Figure 2 provides information that could be relevant for men deciding to be screened or not. It shows that screening reduces a small risk of dying from prostate cancer in the future, at the cost of substantial increased risk of being diagnosed with prostate cancer in the short term.

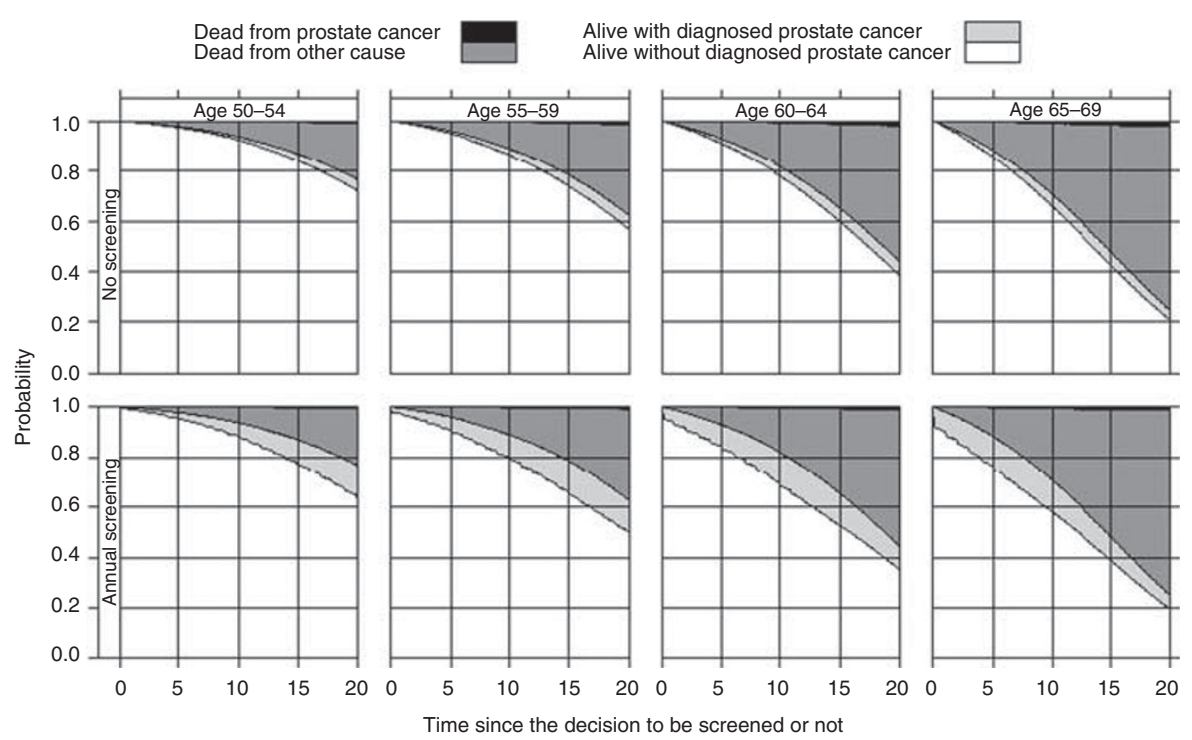

Figure 2 Survival curves with follow-up time from the time of decision. These stacked figures show the proportion of men who are alive without diagnosed prostate cancer (white area), alive with diagnosed prostate cancer (light grey area), dead from prostate cancer (dark grey area) and dead from other causes (black area) at various points in time. 
Table 3 Sensitivity analysis for uncertainty in the model and the data ${ }^{a}$

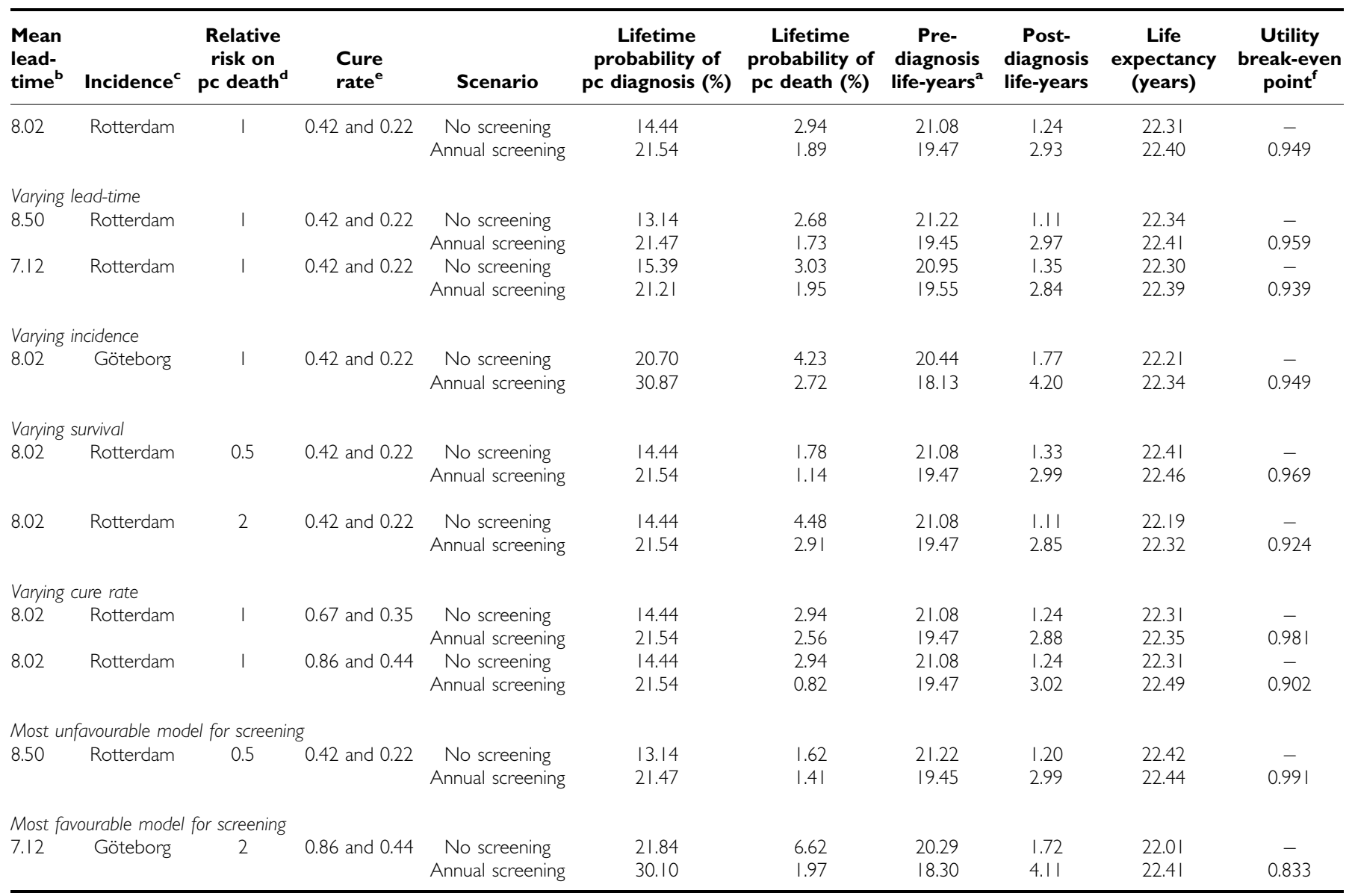

${ }^{a}$ Results are presented for men who were first screened at age 55-59. 'We used penalised optimisation to obtain a range of models with different lead-times (Draisma et al, 2003). 'We varied the incidence in the model by using the estimated incidence parameters that reproduced the incidence in the Netherlands or Sweden. ${ }^{d} \mathrm{~A}$ relative risk of 0.5 on the hazard of prostate cancer death increases prostate cancer-specific survival and a relative risk of 2 on the hazard of prostate cancer death decreases prostate cancer-specific survival. ${ }^{e}$ The cure rates show the proportion of screen-detected men who do not die of pc because their cancer is diagnosed and treated earlier. The cure rates were obtained by calibrating the ERSPC-Rotterdam model to a 10, 27 or 56\% mortality reduction. The first cure rates are for men screen-detected for pc with the Gleason score $\leqslant 7$ and the second cure rates are for men screen-detected for $\mathrm{pc}$ with the Gleason score $>7$. ${ }^{\mathrm{f}}$ The utility break-even point is the value of the utility of living with diagnosed prostate cancer for which the utility-adjusted life expectancy does not change upon deciding to participate in screening or not. Its value decreases with larger gains in overall life expectancy relative to the expected loss in prostate-cancer-free life expectancy. A high value of the utility break-even point means that men should only decide in favour of screening when they anticipate a small loss in quality of life owing to detection and possibly treatment of prostate cancer.

The high utility break-even points $(0.947-0.960)$ in this analysis imply that only a small anticipated loss in quality of life after diagnosing and treating prostate cancer would be acceptable for deciding in favour of screening. As individuals assess the side effects of treatment very differently (Steineck et al, 2002; Korfage et $a l, 2006)$ the anticipated loss in quality of life might vary considerably between individuals. Some patients might find it very important to be potent or continent, for example, because they have an active life that they really want to maintain. Assume a scale from 0 to 100 , where 100 implies that the individual would not mind at all to have sexual problems and 0 implies that the individual would mind very much. An individual whose value is 70 has an expected utility of $0.75(=1 \times 12 /(100-31)+0.70 \times 57 /$ $(100-31))$ in the event that he is diagnosed and treated for prostate cancer and therefore an anticipated loss in quality of life of $25 \%$. This calculation is based on the results of (Korfage et al, 2005) who presented that $31 \%$ of men had erectile dysfunction before radical prostatectomy and $88 \%$ after radical prostatectomy. In this case, the anticipated loss in quality of life after a prostate cancer diagnosis and treatment will be higher than the utility break-even point and therefore the individual should refrain from screening participation. Other patients might find it less important to be potent or continent, which could mean that the anticipated loss in quality of life is lower than the utility break-even point and that therefore the individual should decide to be screened.

Considering the utility break-even point one should, however, acknowledge that expected utility theory is not always a good predictor of patient's actual decisions. Just as with insurance against fire, where the costs are much higher than the expected benefits, people may deem the adverse effects to be acceptable in exchange for the benefits received, while this might not be the case according to expected utility theory. Also, while it is already difficult to assess the loss in quality of life for individuals who are diagnosed and treated for prostate cancer (Essink-Bot et al, 2003), it is probably even more difficult to assess the anticipated loss in quality of life for individuals who are not even screened yet. Therefore, it might be difficult to use the utility break-even points. To be able to use the utility break-even point a formal decision aid should be constructed, which explains the possible side effects of diagnosis and treatment, and which can provide a value for the anticipated loss in quality of life for each individual. For this decision aid published data (Korfage et al, 2005; Stewart et al, 2005; Carlsson et al, 2011) for the risks of the potential side effects of treatment of prostate cancer can be used. 
Another limitation of our study is that the results were calculated using data from a specific population, namely the ERSPC Rotterdam and Göteborg. The results may be different for other populations, as different incidences of and mortalities for prostate cancer have been observed in different countries (Ferlay et al, 2010). The sensitivity analyses give an indication of the expected impact on the results for populations with different incidence, survival and cure rates. In Sweden, prostate cancer accounts for $5.5 \%$ of all causes of deaths among men (The National Board of Health and Welfare, 2009) and the mortality reduction observed in the Göteborg trial was 56\%, among attendees; the expected impact for the Swedish population is therefore comparable to the results of the most favourable model for screening. In the United States, the estimated lifetime risk of prostate cancer diagnosis is $16.22 \%$ and of prostate cancer death is $2.79 \%$ (SEER, 2010), which are close to the main results presented. Therefore, the main results might also be applied in the US population.

The results of this analysis apply to the average population. In this study, we did not do subgroup analyses. However, there might be factors, for example, family history with prostate cancer, obesity and African-American race that imply an increased risk of prostate cancer. Men with these risk factors might have different results for the benefits and harms.

The third limitation is that we used survival curves based on data observed in the United States for the ERSPC-Rotterdam population modelled. We used these survival data as it is one of the few data sets presenting survival of untreated prostate cancer as a function of age at diagnosis and Gleason score progression. However, for our main results we estimated a $2.86 \%$ lifetime risk of prostate cancer death, which corresponds well with US (SEER, 2010) and Dutch data (CBS, 2010).

The fourth limitation is that we did not consider the different treatments available, as there are limited published results about the effectiveness of all treatments. For the purposes of this analysis, we assumed that all individuals diagnosed with prostate cancer received radical prostatectomy. If the effectiveness of active surveillance, radiation therapy or other treatments (e.g., proton beam and brachytherapy) are different than that of radical prostatectomy, the benefits for these treatments will be different than those presented. Also, these might have different potential side effects, which should be taken into account when determining the anticipated loss in quality of life.

If active surveillance is considered an option, treatment might be delayed. This implies that the benefit of screening might be reduced as immediate curative treatment should be at least as

\section{REFERENCES}

Albertsen PC, Hanley JA, Fine J (2005) 20-year outcomes following conservative management of clinically localized prostate cancer. JAMA 293: 2095-2101

Albertsen PC, Moore DF, Shih W, Lin Y, Li H, Lu-Yao GL (2011) Impact of comorbidity on survival among men with localized prostate cancer. J Clin Oncol 29: 1335-1341

Bill-Axelson A, Holmberg L, Ruutu M, Garmo H, Stark JR, Busch C, Nordling S, Haggman M, Andersson SO, Bratell S, Spangberg A, Palmgren J, Steineck G, Adami HO, Johansson JE (2011) Radical prostatectomy versus watchful waiting in early prostate cancer. $N$ Engl J Med 364: 1708-1717

Carlsson S, Aus G, Bergdahl S, Khatami A, Lodding P, Stranne J, Hugosson J (2011) The excess burden of side-effects from treatment in men allocated to screening for prostate cancer. The Goteborg randomised populationbased prostate cancer screening trial. Eur J Cancer 47: 545-553

CBS (2010) Centrale Bureau van Statistieken. http://statline.cbs.nl/ StatWeb/publication/?VW=T\&DM=SLNL\&PA $=03799 \& D 1=291 \& D 2=0 \& D 3=$ 0\&D4=1-9\&HD=120201-1423\&HDR=T\&STB=G1,G2,G3\&CHARTTYPE $=1$ (accessed 1 February 2012)

Dale W, Basu A, Elstein A, Meltzer D (2008) Predicting utility ratings for joint health States from single health States in prostate cancer: empirical testing of 3 alternative theories. Med Decis Making 28: 102-112 effective as delayed curative treatment. In the sensitivity analysis, we considered a scenario where the benefit of screening is reduced (assuming a prostate cancer mortality reduction of $10 \%$ instead of $27 \%$ for screened men). The results for this scenario show the impact on the benefit of screening (0.03 vs 0.09 life-years gained, Table 2) if screening followed by active surveillance would achieve a mortality reduction of $10 \%$. However, as the effectiveness of active surveillance is not known it is not possible to calculate the exact benefits. As with active surveillance the side effects of treatment are postponed the anticipated loss in quality of life will also be lower for the individual.

To evaluate the statistical variation and the uncertainty of the observed data, we performed sensitivity analyses. The models with different lead-times show the statistical variation in the model as we used penalised optimisation to obtain the parameters for these models. The models with different survival curves show the results for populations with worse or better prostate cancer survival. As in the different centres of the ERSPC different prostate cancer mortality reductions has been observed we considered different cure rate estimates. The analysis shows that in populations with worse prostate cancer prognosis and higher cure rates $16.7 \%$ loss in quality of life is still acceptable for an individual to decide in favour of screening, which is quite higher than the $5.1 \%$ in the basecase.

After a median follow-up of 9 years, the ERSPC-trial stated that the prevention of one prostate cancer death entailed the screening of 1410 men (NNS (number needed to screen)), and the additional diagnosis of 48 men (NNT (number needed to treat); Schroder et al, 2009). At 14 years of follow-up, the Göteborg-trial showed that the NNS was 293, and the NNT 12 (Hugosson et al, 2010). Welch and Albertsen (2009) showed that, in the US population in the 1986-2005 period, the NNT was maximally 23 . Using the lifetime risk of prostate cancer diagnosis and death in this study, the average NNS was $101.01(=100 /(2.86-1.87))$ and the average NNT was $7.28(=(21.31-14.10) /(2.86-1.87))$. This illustrates the importance of complete follow-up for correctly estimating these quantities.

In conclusion, the results of the present analysis show that individuals who decide to be screened may lower their risk of dying from prostate cancer and live longer, but also that the associated adverse effects can be significant. However, the magnitude of the adverse effects depends on how undesirable it is for the individual to live with diagnosed and treated prostate cancer and the potential side effects. The negative impact of screening might be reduced by screening men who are more willing to accept the side effects from treatment.
Draisma G, Boer R, Otto SJ, van der Cruijsen IW, Damhuis RA, Schroder FH, de Koning HJ (2003) Lead times and overdetection due to prostate-specific antigen screening: estimates from the European Randomized Study of Screening for Prostate Cancer. J Natl Cancer Inst 95: 868-878

Draisma G, Postma R, Schroder FH, van der Kwast TH, de Koning HJ (2006) Gleason score, age and screening: modeling dedifferentiation in prostate cancer. Int J Cancer 119: 2366-2371

Essink-Bot ML, Korfage IJ, De Koning HJ (2003) Including the quality-oflife effects in the evaluation of prostate cancer screening: expert opinions revisited? BJU Int 92(Suppl 2): 101-105

Ferlay J, Shin HR, Bray F, Forman D, Mathers C, Parkin D (2010) GLOBOCAN 2008, Cancer Incidence and Mortality Worldwide: IARC CancerBase No. 10 International Agency for Research on Cancer. http:// globocan.iarc.fr (accessed on 28 December 2011). Lyon: France

Heidenreich A, Bellmunt J, Bolla M, Joniau S, Mason M, Matveev V, Mottet N, Schmid HP, van der Kwast T, Wiegel T, Zattoni F (2011) EAU guidelines on prostate cancer. Part 1: screening, diagnosis, and treatment of clinically localised disease. Eur Urol 59: 61-71

Heijnsdijk EA, der Kinderen A, Wever EM, Draisma G, Roobol MJ, de Koning HJ (2009) Overdetection, overtreatment and costs in prostate-specific antigen screening for prostate cancer. $\mathrm{Br} J$ Cancer 101: $1833-1838$ 
Hugosson J, Aus G, Lilja H, Lodding P, Pihl CG (2004) Results of a randomized, population-based study of biennial screening using serum prostate-specific antigen measurement to detect prostate carcinoma. Cancer 100: 1397-1405

Hugosson J, Carlsson S, Aus G, Bergdahl S, Khatami A, Lodding P, Pihl CG, Stranne J, Holmberg E, Lilja H (2010) Mortality results from the Goteborg randomised population-based prostate-cancer screening trial. Lancet Oncol 11: 725-732

Korfage IJ, Essink-Bot ML, Borsboom GJ, Madalinska JB, Kirkels WJ, Habbema JD, Schroder FH, de Koning HJ (2005) Five-year follow-up of health-related quality of life after primary treatment of localized prostate cancer. Int J Cancer 116: 291-296

Korfage IJ, Hak T, de Koning HJ, Essink-Bot ML (2006) Patients' perceptions of the side-effects of prostate cancer treatment - a qualitative interview study. Soc Sci Med 63: 911-919

Lim LS, Sherin K (2008) Screening for prostate cancer in US men ACPM position statement on preventive practice. Am J Prev Med 34: 164-170

Parkin DM, Whelan SL, Ferlay J, Raymond L, Young J (1997) Cancer Incidence in Five Continents Vol. VII. IARC Scientific Publications, No. 143 Vol. 5IARC: Lyon

Potosky AL, Legler J, Albertsen PC, Stanford JL, Gilliland FD, Hamilton AS, Eley JW, Stephenson RA, Harlan LC (2000) Health outcomes after prostatectomy or radiotherapy for prostate cancer: results from the Prostate Cancer Outcomes Study. J Natl Cancer Inst 92: 1582-1592

Schroder FH, Hugosson J, Roobol MJ, Tammela TL, Ciatto S, Nelen V, Kwiatkowski M, Lujan M, Lilja H, Zappa M, Denis LJ, Recker F, Berenguer A, Maattanen L, Bangma CH, Aus G, Villers A, Rebillard X, van der Kwast T, Blijenberg BG, Moss SM, de Koning HJ, Auvinen A (2009) Screening and prostate-cancer mortality in a randomized European study. New Engl J Med 360: 1320-1328

SEER (2010) Cancer Statistics Review 1975-2007. National Cancer Institute: Bethesda. http://seer.cancer.gov (accessed September 2011)

Smith RA, Cokkinides V, Brooks D, Saslow D, Brawley OW (2010) Cancer screening in the United States, 2010: a review of current American Cancer Society guidelines and issues in cancer screening. CA Cancer J Clin 60: 99-119

Spapen SJ, Damhuis RA, Kirkels WJ (2000) Trends in the curative treatment of localized prostate cancer after the introduction of prostate-specific antigen: data from the Rotterdam Cancer Registry. BJU Int 85: 474-480

Steineck G, Helgesen F, Adolfsson J, Dickman PW, Johansson JE, Norlen BJ, Holmberg L (2002) Quality of life after radical prostatectomy or watchful waiting. $N$ Engl J Med 347: 790-796

Stewart ST, Lenert L, Bhatnagar V, Kaplan RM (2005) Utilities for prostate cancer health states in men aged 60 and older. Med Care 43: 347-355

The National Board of Health and Welfare (2009) Official Statistics of Sweden. Causes of death 2007. http://www.socialstyrelsen.se/publikationer2009/ dodsorsaker2007 (accessed 29 April 2011)

Visser O, Coeberg JW, Schouten LJ (1994) Incidence of cancer in the Netherlands, 1991. Utrecht (The Netherlands): The Netherlands Cancer Registry 13: 45

Welch HG, Albertsen PC (2009) Prostate cancer diagnosis and treatment after the introduction of prostate-specific antigen screening: 1986-2005. J Natl Cancer Inst 101: 1325-1329

Wever EM, Draisma G, Heijnsdijk EA, de Koning HJ (2011) How does early detection by screening affect disease progression?: modeling estimated benefits in prostate cancer screening. Med Decis Making 31: 550-558

Wever EM, Draisma G, Heijnsdijk EA, Roobol MJ, Boer R, Otto SJ, de Koning HJ (2010) Prostate-specific antigen screening in the United States vs in the European Randomized Study of Screening for Prostate CancerRotterdam. J Natl Cancer Inst 102: 352-355

Wolf AM, Wender RC, Etzioni RB, Thompson IM, D’Amico AV, Volk RJ, Brooks DD, Dash C, Guessous I, Andrews K, DeSantis C, Smith RA (2010) American Cancer Society guideline for the early detection of prostate cancer: update 2010. CA Cancer J Clin 60: 70-98

This work is published under the standard license to publish agreement. After 12 months the work will become freely available and the license terms will switch to a Creative Commons Attribution-NonCommercial-Share Alike 3.0 Unported License. 